\title{
Covid-19: Lack of test and trace data is frustrating government scrutiny
}

\author{
Shaun Griffin
}

London, UK

Former health secretary Jeremy Hunt has responded with incredulity at the lack of data about the government's test and trace programme, after the head of the service was unable to provide figures on how many tests had been completed within the first 24 hours.

The UK stopped community testing and contact tracing for covid-19 in early March, partly because of a lack of capacity. ${ }^{1}$ But after pressure from public health experts a new programme was launched on $28 \mathrm{May}^{2}$ to great fanfare from Prime Minister Boris Johnson who said it would be "world beating."

At an evidence hearing of the House of Commons Health and Social Care Committee on 3 June, Hunt said that Dido Harding, chair of NHS Test and Trace, had been given advance notice of four questions, including one requesting data on the proportion of tests completed in 24 hours.

Giving evidence, Harding said, "This is a service that is only six days old and we need to make sure any data are accurate and validated," adding, "I just don't have those statistics at a level that would pass the test of our UK Statistics Authority."

She referred to a letter from the chair of the UK Statistics Authority to health secretary Matt Hancock which criticised the government's approach to communicating data on testing. ${ }^{3}$

Harding expressed discomfort in sharing unvalidated figures but said she was working with the UK Statistics Authority and was "close to agreeing a weekly dashboard for test and trace data, but I don't have the data to share today." She promised it next week if the data can be validated.

In response, Hunt said, "We did give you notice. This is a House of Commons select committee and we were told it was a world beating system when it was launched, so I don't think it is unreasonable to ask quite simple questions."

He went on to say, "What no one wants to tell us is the overall proportion of tests that come back within 24 hours. You must know that. That just can't be right. You're telling me you don't know how many tests come back within 24 hours and you're in charge of NHS Test and Trace?

"Our frustration is that it is very hard for us to scrutinise what the government is doing if we're not given the data that allow us to do that."

Harding was able to give some qualitative data, saying that, of the thousands of people contacted in the first six days, the vast majority of those asked to isolate were happy to do so. She noted that of the estimated 8000 people contracting covid- 19 every day, 1600 are currently being tested. She expressed concern, however, that a recent survey showed that $44 \%$ of adults are not aware that anyone who has symptoms can order a test.

\section{Need for rapid testing}

Also giving evidence, Christophe Fraser, professor of pathogen dynamics at the University of Oxford, noted that the UK was now transitioning from a "stay at home" message to one of rapid testing and contact tracing which "has been adopted by countries with best practice." Countries that mobilised that approach from the outset have fared better, he said, and have an advantage because "it's easier to maintain very rapid and efficient testing and tracing when the number of cases is relatively limited."

When asked how quickly contact tracing needs to happen, Fraser said that because the covid-19 incubation period is typically 5-7 days, with infectiousness starting around two days before symptoms develop, as long as people ask for a test within two days of symptom onset, you have "about four days from the index case developing symptoms to getting the message to people before they start infecting others." Requesting a test after two days would leave only a short window to complete the test and trace process.

"If you have a delay in two days beyond that, you have lost a third of contact tracing potential; in another two days you've lost another third; and if you wait for six days any contacts would have gone through their infection," he added.

\section{Correction: On 5 June we clarified the timings given in the penultimate} paragraph.

1 lacobucci G. Covid-19: Lack of capacity led to halting of community testing in March, admits deputy chief medical officer. BMJ 2020;369:m1845. 10.1136/bmj.m1845 32376638 Mahase E. Covid-19: How does the NHS test and trace service work?BMJ 2020;369:m2174. 10.1136/bmj.m2174 32471822

3 Wise J. Covid-19: Chief statistician criticises government over reporting of testing. BMJ 2020;369:m1664. 10.1136/bmj.m1664 32341080

This article is made freely available for use in accordance with BMJ's website terms and conditions for the duration of the covid-19 pandemic or until otherwise determined by BMJ. You may use, download and print the article for any lawful, non-commercial purpose (including text and data mining) provided that all copyright notices and trade marks are retained.

https://bmj.com/coronavirus/usage 